\title{
OPTIMIZATION OF EMERGENCY EVACUATION IN FIRE BUILDING BY INTEGRATED BIM AND GIS
}

\author{
S. Atyabi ${ }^{1}$, M. Kiavarz Moghaddam ${ }^{2, *}$, A. Rajabifard ${ }^{3}$ \\ ${ }^{1}$ Dept. of GIS \& Remote Sensing, Geography Faculty, University Tehran, Tehran, Iran - sara.atyabi@ut.ac.ir \\ ${ }^{2}$ Dept. of GIS \& Remote Sensing, Geography Faculty, University Tehran, Tehran, Iran - kiavarzmajid@ut.ac.ir \\ ${ }^{3}$ Center for Disaster Management and Public Safety (CDMPS), Department of Infrastructure Engineering Univesity of Melbourne, \\ Parkville VIC 3010, Australia - abbas.r@unimelb.edu.au
}

\section{Commission VI, WG VI/4}

KEY WORDS: Indoor Navigation, Fire Evacuation, 3D Modelling, BIM, GIS

\begin{abstract}
:
Building Information Model (BIM) is a database, which makes a detailed 3D geometrical model with rich semantic information of building, go beyond the standard Computer-Aided Design approach. BIM could be as an ideal source to store, formation model and analyses spatial information of internal environments. GIS is an effective tool for analysing the constant and dynamic variables in small areas such as indoor environments. Therefore, integration of the BIM and GIS is useful for integrating the internal environment and networks for designing optimal routes in emergency evacuation problems. Increasing complexity of high-rise buildings and underground structures lead to much more complication in urban disaster management. One of the main challenges in disaster management and emergency evacuation is to guide people in optimal routes to reach safe areas. In this paper, in order to create optimal routes in internal environments and create an internal geometric network model based on the internal nodes and edges, BIM of a 3D commercial building located in the 8th district of Tehran, was made and transferred to the ARCGIS that enables us to use routing algorithms to find the optimize routes between both internal positions. Flammability, occupancy load, width of exit access and distance of fire point criteria were considered to find the safest routes in emergency evacuation times. Network Analysis and Ant Colony's algorithm were applied for finding the safest routes. The results indicated that the Network Analysis was better in terms of processing time and finding short and safe paths related to the Ant Colony's algorithm.
\end{abstract}

\section{INTRODUCTION}

\subsection{Background}

With the quick development of urbanization, people are spending most of their time indoors, either inside their office, homes, or other structures such as shopping centres, metro stations, etc. In addition, the increasing complexity of high rise buildings and underground structures lead to much more complication in urban disaster management. According to statistics the National Fire Protection Association (NFPA) in 2012, 480,500 structure fires were reported in the United States causing 2,470 civilian deaths, 14,700 civilian injuries and 69,400 firefighter injuries which resulted in a total loss of $\$ 9.8$ billion in property damage billion in property damage (NFPA, 2013). Which result in tragic consequences for people, their assets and the environment.

The problem of planning for emergency evacuation due to the need to move the population to damage the safe areas (Cova and Johnson, 2003). Previous research mainly look at indoor evacuation systems from two points of view. One is simulating fire models and the other is modelling the indoor environment. Graph networks are used for modelling evacuation and routing in many indoor navigation platforms proposed (Rüppel et al., 2014; Karas et al., 2006; Jun et al., 2009) while most 3D visualization problems use Lee's Node-Relation Structure model (Lee, 2001) which integrates the topological model of the network with the geometric information to form the geometric network model which enables visualization and cost (based on distance or optimality) computation (see Fig 1). One of the main challenges in disaster management and emergency evacuation is to guide people in optimal routes to reach safe areas.

Emergency evacuation and route planning in an indoor environment are heavily dependent on the data network model and require detailed indoor information that is usually obtained from the architecture, engineering, and construction (AEC) industry ground plans. As an emerging technology in the AEC domain, the building information model (BIM) is implemented over the entire building life cycle (Volk et al., 2014; Cerovsek, 2011). In addition, BIM improves route planning because it contains specific geometrical and semantic (attributes) information of building components and can be treated as an ideal source of spatial indoor information.

Geographic Information System (GIS) integrates spatial information and spatial analysis for different applications (Bansal \& Pal, 2007). In fact, GIS has been proven to be effective in analysing static and dynamic variables in small regions such as indoor environment (Tang \& Ren, 2011). While GIS is mostly used on open spaces, the rise of threedimensional (3D) indoor GIS allows for the technology to be applied in an indoor setting such as emergency management planning (Cao and $\mathrm{Lu}, 2012$ ). Network analysis is a tool that GIS specialists use in order to solve transportation problems. This can be used for indoor navigation, with the 3D aspect adding dimension and spatiality (Musliman et al., 2008).

Therefore, integration of the BIM and GIS is useful for integrating the internal environment and networks for designing optimal routes in emergency evacuation problems. To achieve

\footnotetext{
${ }^{*}$ Corresponding author
} 
interoperability between these two environment, they use an open standard format called IFC.
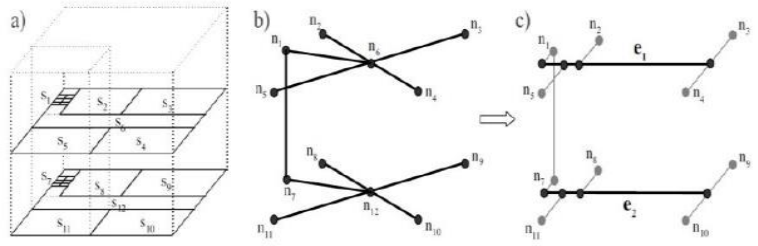

Fig 1. Building the geometric network model (a) 3D building model (b) topologic model (c) geometric network model

\subsection{Objectives}

This study aims to perform 3D network analysis and Ant Colony algorithm in a generated geometric 3D indoor BIM model of the commercial building located in the 8th district of Tehran to assess the current fire evacuation plan of the building. scenarios will also be considered from which evacuation safest routes will be generated by considering the indoor parameters of the building, such as load occupancy, flammability and width of exit access for each scenario. These new routes will be evaluated and compared for length, process time and evacuation time.

\section{REVIEW OF RELATED LITERATURE}

\subsection{Emergency management and Path-finding}

Most of research on emergency evacuation in a building environment is focused on rescue and evacuation, which are related to path finding and indoor navigation (Kwan \& Lee, 2005; Lee, 2007; Liu \& Zlatanova, 2012; Vanclooster et al., 2014). Different researchers focus on different aspects of evacuation: least risk paths (Vanclooster et al., 2014), path simplicity (Duckham \& Kulik, 2003), navigable network improvement (Kwan \& Lee, 2005; Lee, 2007), more detailed routes (Liu \& Zlatanova, 2012), and human behaviour (Choi \& Lee, 2009). Evacuation routes for both patrons and library staff were generated with shortest distance and time to reach an exit point as the parameters for the creation of the routes (Gelido et al., 2018).

\subsection{D Network Analysis}

3D network analysis can be used to find the shortest path within indoor spaces for emergency management in complex, multilevel buildings (Cao and Lu, 2012). A network-based model makes use of nodes and edges - where nodes represent building units and edges represent the distance between the two units or nodes. Rooms are then represented by nodes, while the flow of people are represented by the edges. The people travel between nodes until they reach and exit node for evacuation. The minimum calculations required and fast computing speed of this model makes it advantageous to use, but it does make for a very simple representation of movement (Xiong et al., 2017).

\section{PROPOSED METHOD}

\subsection{Case Study}

The building under study is a 6-story commercial building in the 8th district of Tehran, called SevenCenter, that with an area of about 2000 square meters, located in the east of Tehran, Narmak district, Haft Hoz square, intersection of Dr. Ayat St. and West Rezvan street. The commercial building has 180 commarcial units with different uses and has two emergency exit stairs on the north side and three exit doors on the north and east sides as well as two elevators on the north side of the building.

\subsection{D Building Model and Geometric Network Model}

The general methodology of the study can be seen in Figure 2 . In order to response and evacuate and create optimal paths in the interior of the building, 2D indoor CAD files are first converted to 3D building models using Revit. Revit is an architectural software that gives the ability to build three dimensional building models enhanced with various types of structural and engineering information for Building Information Modelling.

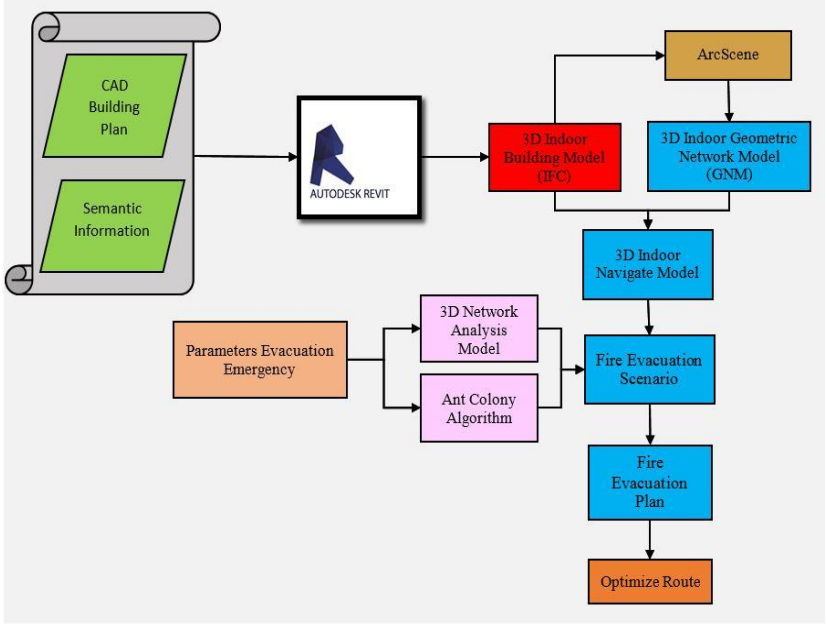

Fig 2. General metodology

At this stage, Information regarding emergency utilities and semantic information can be added to the 3D building model. The resulting model can be exported to IFC (Industry Foundation Classes) format which is an open, international, and standardized specification for Building Information Modelling (BuildingSmart, 2008). Revit allows addition of furnishing elements, architectural features, indoor space definition, staircases, etc. which help in detailed modelling of inside of the buildings. The 3D building elements are then exported to the Esri geodatabase format by using the Data Interoperability extension in ArcGIS. Each IFC entity is represented as a layer holding that entities' attributes in its attribute table. Then, the 3D indoor geometric network model (GNM) is created for the building and together with the indoor building model, a 3D indoor navigable model is provided. Finally, 3D Network Analyst enables us to find optimized routes between both internal position using the $3 \mathrm{D}$ navigable model in the emergency evacuation scenario. When evacuate algorithms are used in the researches, There is always a spatial model in the background (see figure 1a). A building structure is represented as a logical network, where its nodes represent rooms, including corridors and other navigable areas; and edges represent navigable connections between adjacent rooms (see figure $1 \mathrm{~b}$ ). The network can be further improved into a geometric network in order to reflect real navigation routes and more precise geometric properties e.g. distance between nodes (see figure 1c) (Kwan and Lee, 2005). This representation allows applying graph algorithms as Dijkstra's algorithm for shortest path finding in evacuation planning. 


\subsection{Route Safety Criteria in the Building}

In order to determine route safety criteria, we used Book III topic of the National Building Regulations (Protection Building against Fire). In this paper, quantitative criteria of occupancy load, exit width access and distance of fire point were considered as effective parameters in determining safe routes for emergency evacuation in a building fire. As well as, according to investigation the research on the Plasco building fire incident in Tehran and the existence of low flammable materials as a cause of fire, we also consider the flammability parameter to be an effective criterion.

\subsection{Emergency Evacuation Scenario in Fire Building}

According to the experts of the fire department, a general scenario for emergency evacuation in the building fire was created which according to this scenario and according to the experts of the fire department, the electrical connection can be the most important factor in starting a fire in a building, 6 scenarios were considered, for each floor a fire scenario that was based on the probable location where the fire incident might start from that point, a specific point in each floor, and the exit point of doors and windows were considered where the routing algorithms of Network Analysis and Ant Colony based on these scenario on the network structure in order to creat the shortest and safest routes were implemented.

\subsection{Network analysis model design}

In order to maintain the network analysis, each node and segment of all the feature should connect to each other. In this research, a route analysis model was created that was designed to perform $3 \mathrm{D}$ routing. then route safety parameters and their weights were applied through the network dataset. A route layer and a stops layer, which is the position of the beginning and end points, and solve tool were created in ArcCatalog by the ModelBuilder and ArcGIS Network Analysis tools. Figure 3 shows the created route analysis model of 3D network analysis.

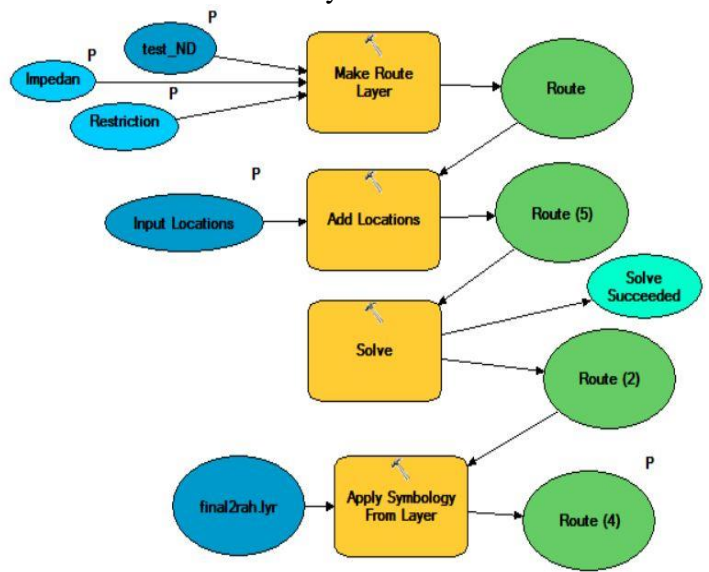

Figure 3. Route model of 3D network analysis

\subsection{Ant Colony Optimization}

"ACO is a meta-heuristic technique that uses artificial ants to find solutions to combinatorial optimization problems. ACO is based on the behavior of real ants searching a path between their colony and a source of food" (Claes, et al., 2011). In the real words ants move around their colony and search for food and release a chemical substance named "Pheromone". This substance attracts other ants, so when a food be found somewhere, the ants follow the first ant that found the food and more ants attracts to the food and that route be desired one; so many ants move on that route. This behavior can be simulated in computational problems. Some initial answers can be considered, then in an iteration a positive score added to good answers and bad answers have been deleted. This process will continued until best answer be found.

There is an important step in this process called "pheromone update" which mentioned above. In each step a positive score will be added to all answers, so good answers get more pheromone than other answers, so the good answers risen and at the end of iteration the best answer will be found. Also these pheromones will not remain permanently and they will disappear slowly. This process is evaporation and there is a parameter in ACO algorithm that called "evaporation rate". Because of the nature of route finding problem, it's very similar to ant's movements; so the Ant Colony Optimization algorithm is very useful in route finding. A route includes some nodes (like $i, j$...) and edges. In simple ACO the value of an edges corresponded with its length. The pheromones considered for each edge as a value. Several routes between origin and destination will considered and evaluated. Better solutions attracts more pheromones in pheromone update process so that at the end of iteration the best route attracts most pheromone and introduced as best solution between two points. And then the shortest path between two points will be found. Pheromone update equation is:

$\tau_{\mathrm{ij}}(\mathrm{t}+1)=(1-\rho) \cdot \tau_{\mathrm{ijj}}(\mathrm{t})+\Delta \tau_{\mathrm{ij}}$

Where $\rho$ is evaporation rate.

$\Delta \tau_{\mathrm{ij}}^{\mathrm{k}_{\mathrm{ij}}}(\mathrm{t}, \mathrm{t}+1)=\mathrm{Q} / \mathrm{d}_{\mathrm{ij}}$

Where $\mathrm{Q}$ is a constant, $\mathrm{d}_{\mathrm{ij}}$ is route length of $\mathrm{k}$-th ant.

The probability $\mathrm{p}_{\mathrm{ij}}$ of the $\mathrm{k}$-th ant moving from point $\mathrm{i}$ to $\mathrm{j}$ is:

$$
p^{k_{i j}}=\frac{\left[\tau_{i j}\right]^{\alpha} \cdot\left[\eta_{i j}\right]^{\beta}}{\sum\left[\tau_{i j}\right]^{\alpha} \cdot\left[\eta_{i j}\right]^{\beta}}
$$

This function determines the probability of selecting the next node and calculates for all nodes that $\mathrm{k}$-th ant has the choice of $\mathrm{i}$ node and based on the maximum value for this function from $\mathrm{i}$ to the selected node. Based on the value of this function, the motion continues. In order to implement the ant colony algorithm on the three-dimensional geometric network model, the following condition was considered for the effect of ants pheromones on each other so that we could find the optimal paths (shortest and safest) that pi the probability of the initial foramen. And pf is the pneumatic effect of each ant on the other ant. If we reach the staircase node and pi is smaller than pf, we move down to the nearest staircase and if pi equals pf On the same floor, we choose the most optimal path, and then if we reach the staircase node and pi is larger than pf, move up. Otherwise we will move to the nearest staircase (see Figure 4).

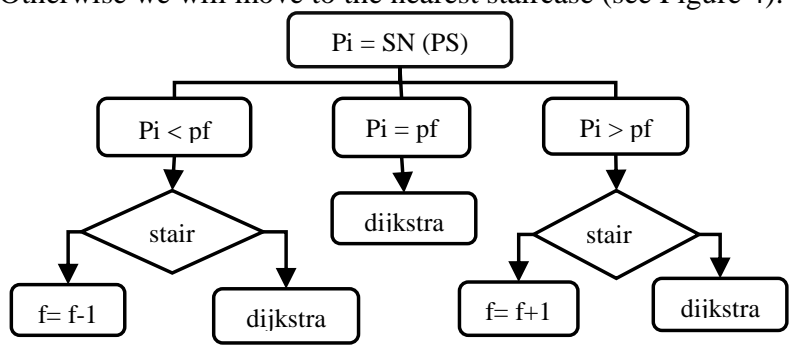

Figure 4. Condition created in Ant Colony algorithm 


\subsection{Evacuation Time}

As the traversing speed of various segments on the network is different, the problem of finding the optimum route could not be bounded finding the shortest path. That is, considering walking speed on horizontal indoor floors, vertical speed on stairs, the problem of finding the best route in the context of emergency would be to find the fastest and safest route towards the destinations. Thus, we have based the cost of each edge on the time it takes to traverse that edge which can be derived from the following formula:

$$
\mathrm{t}_{\mathrm{e}}=\mathrm{D}_{\mathrm{e}} / \mathrm{S}_{\mathrm{e}}
$$

where $t_{e}=$ time to traverse edge

$D_{\mathrm{e}}=$ distance of edge

$\mathrm{S}_{\mathrm{e}}=$ speed of traversing the edge

Travelling speeds in the network are assumed to be $1.20 \mathrm{~m} / \mathrm{s}$ for horizontal indoor walking speed, and $0.8 \mathrm{~m} / \mathrm{s}$ for climbing stairs. The quickest and safest path between any two points is calculated using the Dijkstra and Ant Colony algorithms with the aforementioned edge costs. Accordingly the fastest route between two point is the path with the minimum total traversing time based on the following formula:

$T=\sum_{i=1}^{n}\left[\left(D_{\text {horizontal }} / S_{\text {walking }}\right)+\left(D_{\text {vertical }} / S_{\text {stair }}\right)\right]$

where $\quad \mathrm{T}=$ total traverse time

Dhorizontal $=$ distance walked horizontally indoors

$S_{\text {walking }}=$ horizontal indoor walking speed

$D_{\text {vertical }}=$ distance walked vertically indoors

$S_{\text {vertical }}=$ vertical indoor walking speed

\section{3D MODELLING}

\subsection{Building Information Model}

In this paper, we selected the SevenCenter shopping center in district 8 of Tehran as a pilot site examine and demonstrate the integration of BIM and GIS for emergency evacuation analysis in the indoor environment. The main input for the $3 \mathrm{D}$ modelling was the commercial building floor plan in CAD format. Figure 5 shows the 3D modelling results of the SevenCenter commercial Building Information Model (BIM) in Revit software.

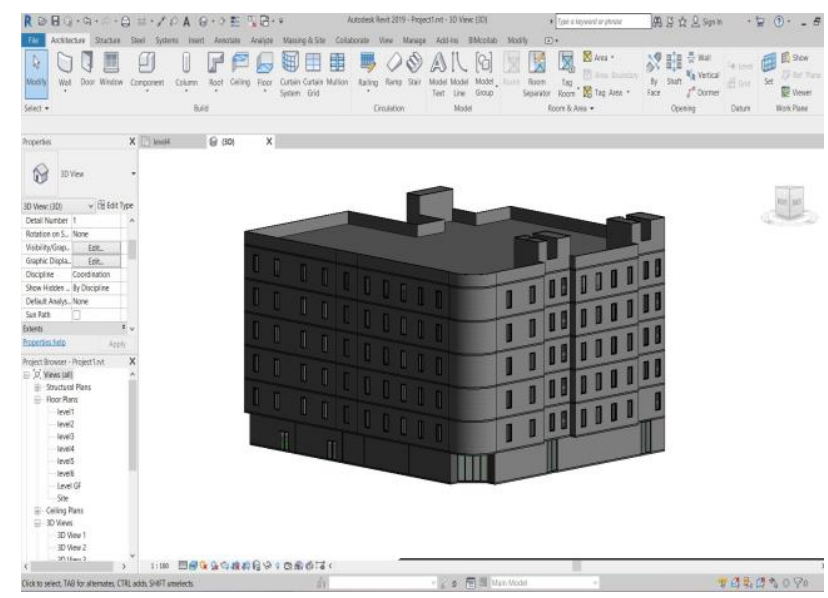

Figure 5. BIM of SevenCenter commercial building

\subsection{Geometric Network Model}

To simulate the motin and structure of the building, a Geometric Network Model (GNM) was constructed. Creating a geometric network model has advantages, but for this research, the ability to calculate the shortest and safest route between two point was the most important issue. To creat the geometric network model, the nodes representing each commercial unit, corridors and stairs were digitized in order to routing analysis on all floor of the building. Finally, after digitizing the network structure of each floor separately and connection them through the stairs, the overall structure of the geometric network model of the commercial building on which routing was performed, was obtain (see Figure 6).

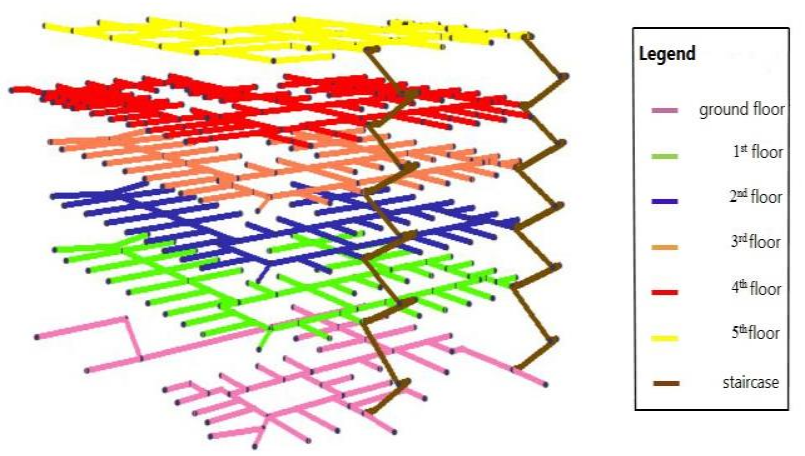

Figure 6. Geometric network model

\section{RESULT}

\subsection{Routing Test of Fire Scenario Using Network Analysis}

In order to evaluate the capabilities of the proposed optimal routing mathods to find the shortest and safest route for emergency evacuation and transport people to safe location, these methods are implemented on geometric network model based on fire building scenarios and their results listed in the following sections. In this building, evacuate cannot be done from the roof due to the lack of alignment of the commercial building with the adjacent building as well as the arched roof. Also, in case where evacuation was done from the window, half of the time the fire truck arrived from the station to the building was added to the evacuation time.

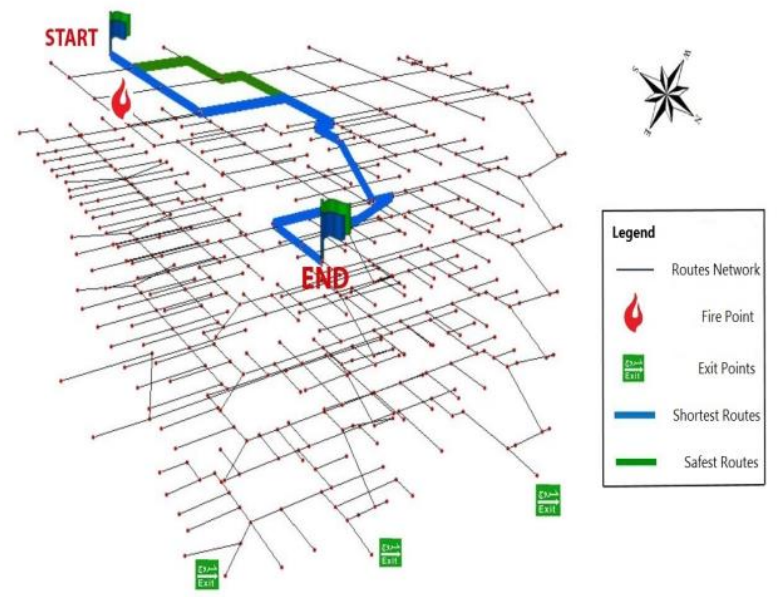

Figure 7. Scenario 1: Shortest route (blue); Safest route (green) 
5.1.1 Scenario 1: In this scenario, it is assumed that a fire occurred on the fifth floor of a commercial building, that is the last floor of the building and a foodcourt, and there was a fireladder proportional with the height of the floor fourth. Thus, in this scenario the only evacuate route, moving down the staircase and priority, is the nearest lower floor window, which is the starting point for the emergency evacuation route of the number node 351 is located in the restaurant, and evacuate is take place from node 322 through the lower floor window, the fourth floor (see Figure 7). In this scenario the processing time for the shortest and safest routes is 2.10 and 2.33 seconds respectively, the length of shortest and safest routes 86.502 and $86.531 \mathrm{~m}$ and the evacuate time is based on formula number 5 for the shortest and safest routes was obtain $77.85+125$ and $77.87+125$ seconds, respectively.

5.1.2 Scenario 2: In this scenario, it is assumed that the fire occurred on the fourth floor and in the electrical room and the up and down path of the staircase was blocked but there was the fire-ladder proportional with the height of the fourth floor. The starting point of the evacuate route at node 183 is located at commercial unit number 180 and the evacuate is take place from nodes 101 and 225 through the window of the same floor for the shortest and safest route, respectively (see Figure 8).
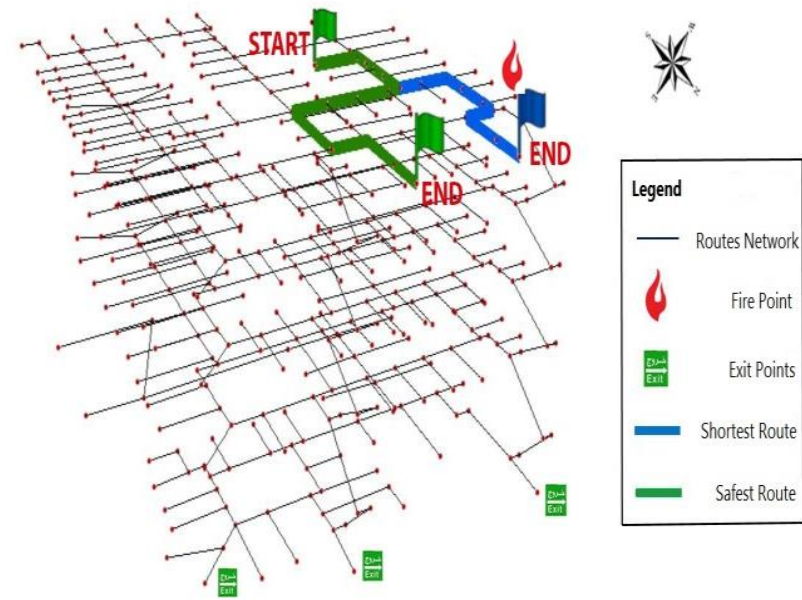

Figure 8. Scenario 2: Shortest route (blue); Safest route (green)

In this scenario the processing time for the shortest and safest routes is 1.48 and 1.62 seconds respectively, the length of shortest and safest routes 41.929 and $48.916 \mathrm{~m}$ and the evacuate time for the shortest and safest routes was obtain $34.93+125$ and $40.76+125$ seconds, respectively.

5.1.3 Scenario 3: In this scenario, it is assumed that a thirdfloor fire occurred in a computer service unit and that the down path to the staircase was blocked and that the windows of the same floor could not be evacuated. Up path the staircase is open and there is a fire-ladder proportion with the height of the fourth floor. The starting point for the node evacuate route 431 is located in unit 101 and the evacuate is take place from node 322 is done through the upper floor window (see Figure 9). In this scenario the processing time for the shortest and safest routes is 1.88 and 2.01 seconds respectively, the length of shortest and safest routes 83.354 and $83.476 \mathrm{~m}$ and the evacuate time for the shortest and safest routes was obtain $75.21+125$ and $75.31+125$ seconds, respectively.

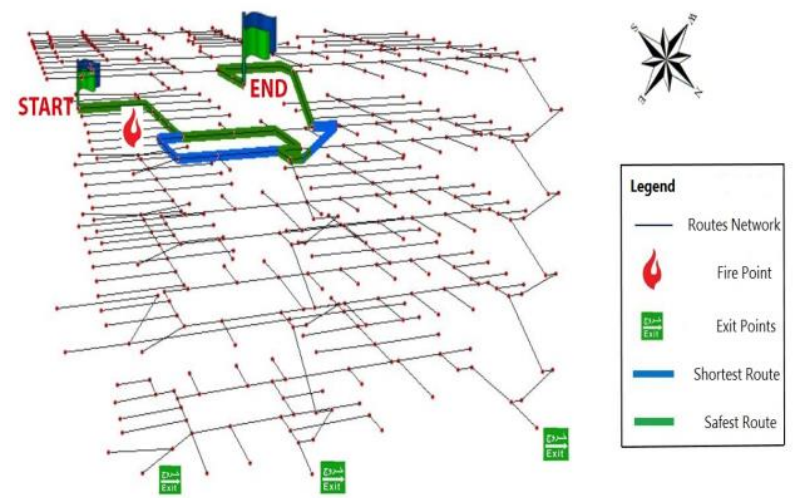

Figure 9. Scenario 3: Shortest route (blue); Safest route (green)

5.1.4 Scenario 4: In this scenario, it is assumed that a second-floor fire occurred in a lustre commercial unit and that the up path of the staircase was blocked and that the window of the same floor could not be evacuated. Down path of the stairs is open. The starting point of the node evacuate path is 144 point in the corridor and the evacuate is take place from nodes 491 and 490 means the exit gates 2 and 3 for the safest and shortest routes, respectively (see Figure 10).

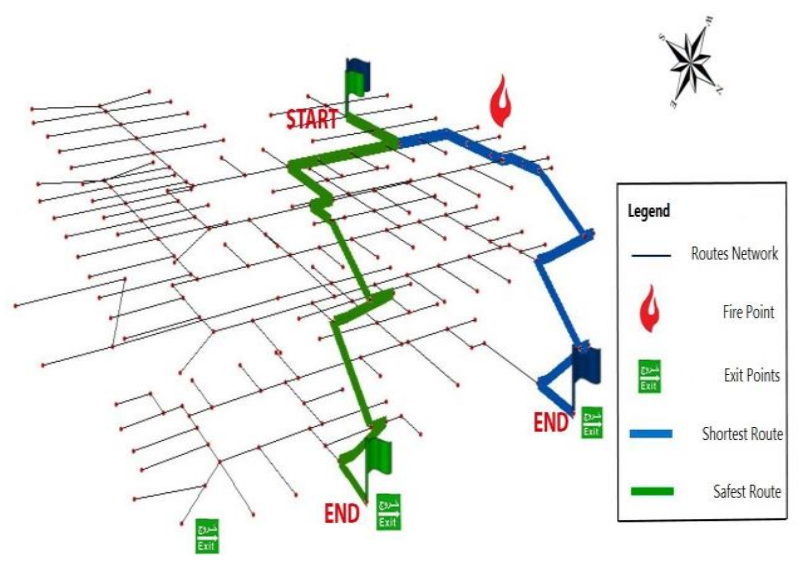

Figure 10. Scenario 4: Shortest route (blue); Safest route (green)

In this scenario the processing time for the shortest and safest routes is 1.79 and 1.92 seconds respectively, the length of shortest and safest routes 63.934 and $72.876 \mathrm{~m}$ and the evacuate time for the shortest and safest routes was obtain 64.23 and 71.68 seconds, respectively.

5.1.5 Scenario 5: In this scenario, it is assumed that the firstfloor fire occurred in a audio-visual commercial unit, and both routes are open staircase, due to the proximity to the exit gates, down path of the staircase is selected. The starting point of the node evacuate route is 188 , point in the corridor, and the evacuate is take place from nodes 491 and 490 means the exit gates 2 and 3 of the building for the safest and shortes routes, respectively (see Figure 11). In this scenario the processing time for the shortest and safest routes is 1.53 and 1.56 seconds respectively, the length of shortest and safest routes 42.233 and $44.92 \mathrm{~m}$ and the evacuate time for the shortest and safest routes was obtain 40.74 and 42.99 seconds, respectively. 


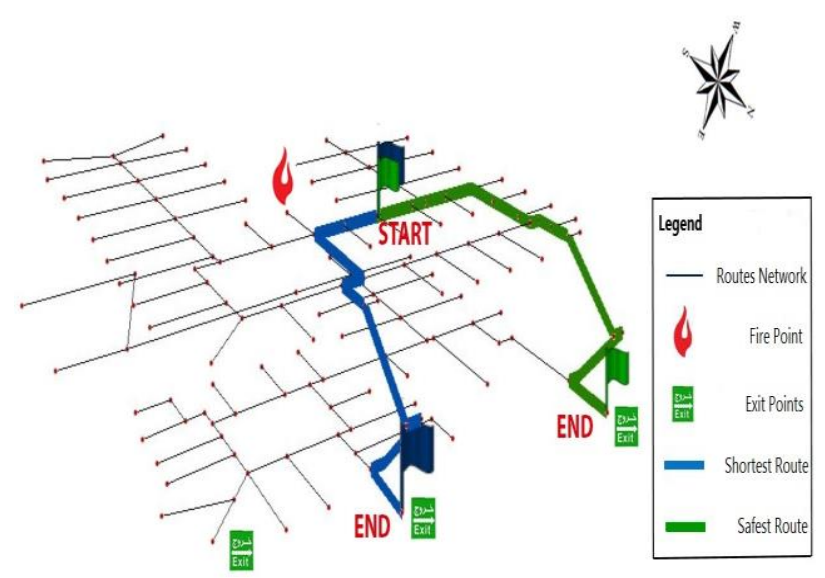

Figure 11. Scenario 5: Shortest route (blue); safest route (green)

5.1.6 Scenario 6: In this scenario, it is assumed that the fire occurred on the ground floor and in the facility room, and exit gates 2 and 3 being blocked and the only outlet is gate number 1. The point of evacuate at node 83 is located in the corridor, and the evacuate is take place at point 417 means the exit gate 1 (see Figure 12)
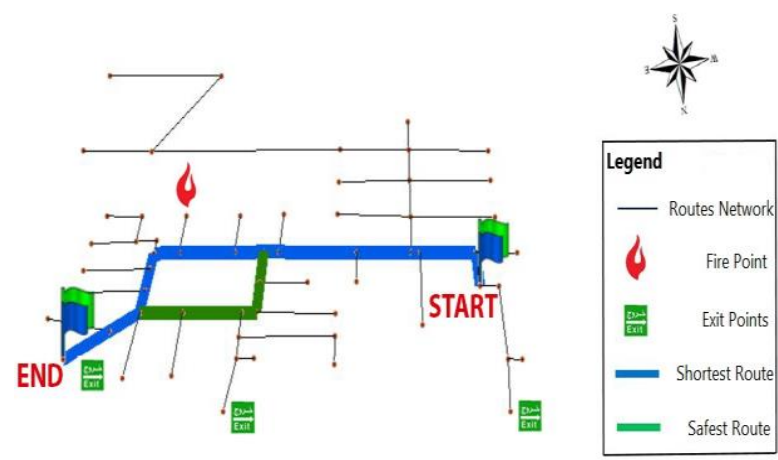

Figure 12. Scenario 6: Shortest route (blue); Safest route (green)

In this scenario the processing time for the shortest and safest routes is 1.42 and 1.59 seconds respectively, the length of shortest and safest routes 45.889 and $46.06 \mathrm{~m}$ and the evacuate time for the shortest and safest routes was obtain 38.24 and 38.38 seconds, respectively.

\subsection{Routing Test of Fire Scenario Using Ant Colony Algorithm}

In order to the performance of Ant Colony algorithm on 3D geometric network model, this algorithm was tested on geometric network model based on building fire scenarios in MATLAB software environment. 494 nodes and 518 edges were used for implementation and testing as well as edges length and edges weight that could be extracted from ARCGIS software in Exel file format. Figure 13 shows the 3D structure of the geometric network model in the MATLAB software environment. In the next step, we defined the basic parameters of the algorithm, such as the number of ants, the number of iterations and the rate of evaporation that were assumed to be 10,10 and 0.1 , respectively. Then the number of the primary node and the end node are introduced to the algorithm as a safe point. In the following we shows the routing results, which include the route length, processing time and nodes passed by the route, respectively, for the same 6 fire building scenarios we performed in the ARCGIS environment.

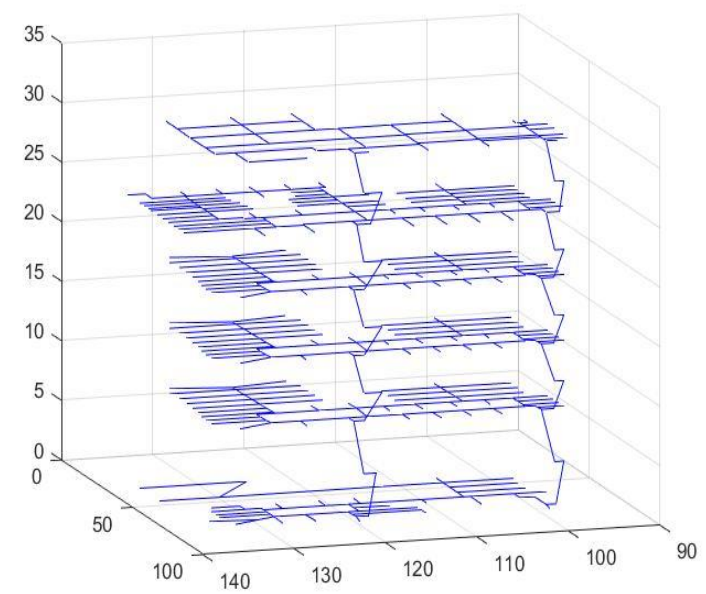

Figure 13. Geometric network model in MATLAB software

5.2.1 Scenario 1: In this scenario, it is assumed that a fire occurred on the fifth floor of a commercial building and the evacuate is take place from node 322 through the lower floor window, the fourth floor (see Figure 14).

a)

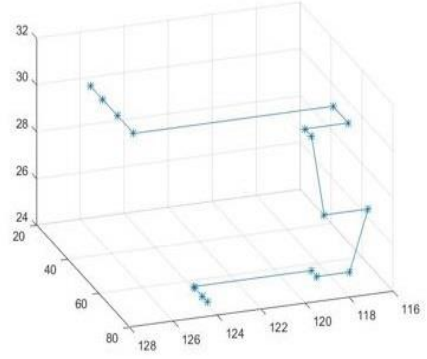

Best Fitness $=86.502$

Time $=26.3615$

PATH $=$

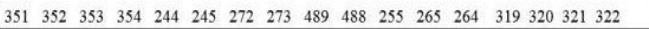

b)

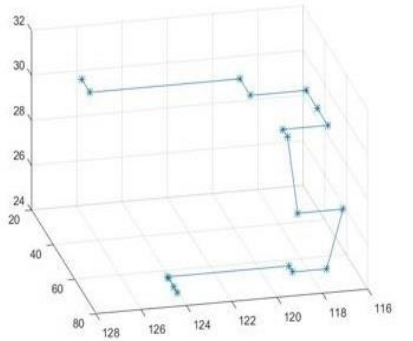

Best Fitness $=86.531$

Time $=26.6053$

PATH $=$

351352290291243244245272273489488255265264319320321322 |

Figure 14. Shortest route (a) Safest route (b)

5.2.2 Scenario 2: In this scenario, it is assumed that the fire occurred on the fourth floor and in the electrical room and the evacuate is take place from nodes 101 and 225 through the window of the same floor for the shortest and safest route, respectively (see Figure 15). 


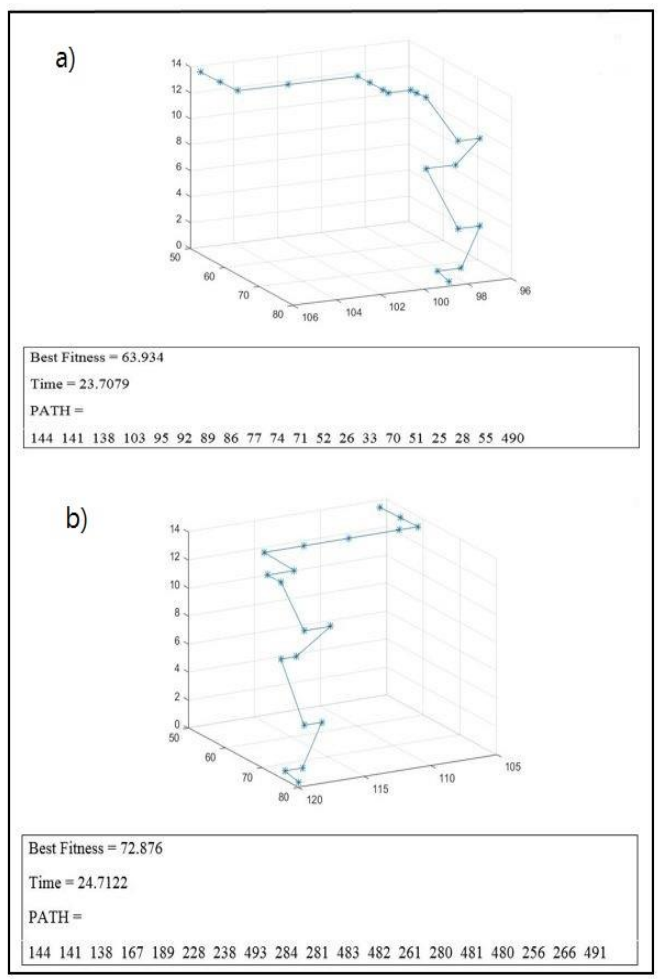

Figure 15. Shortest route (a) Safest route (b)

5.2.3 Scenario 3: In this scenario, it is assumed that a thirdfloor fire occurred in a computer service business and the evacuate is take place from node 322 is done through the upper floor window (see Figure 16).

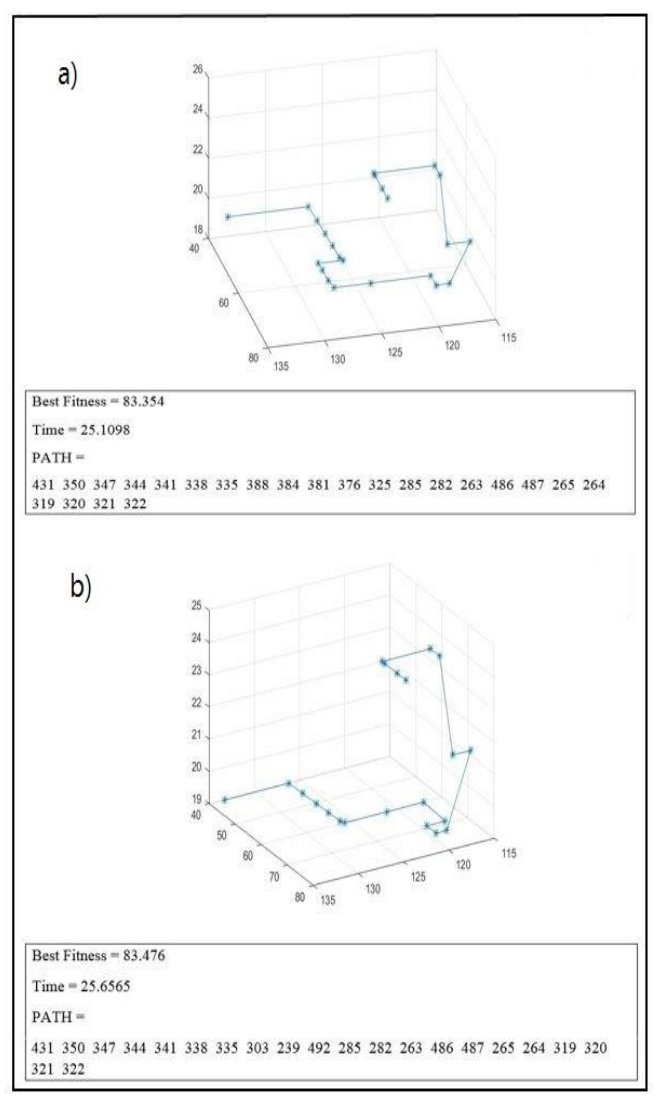

Figure 16. Shortest route (a) Safest route (b)
5.2.4 Scenario 4: In this scenario, it is assumed that a second-floor fire occurred in a lustre commercial unit and the evacuate is take place from nodes 491 and 490 means the exit gates 2 and 3 for the safest and shortest routes, respectively (see Figure 17).

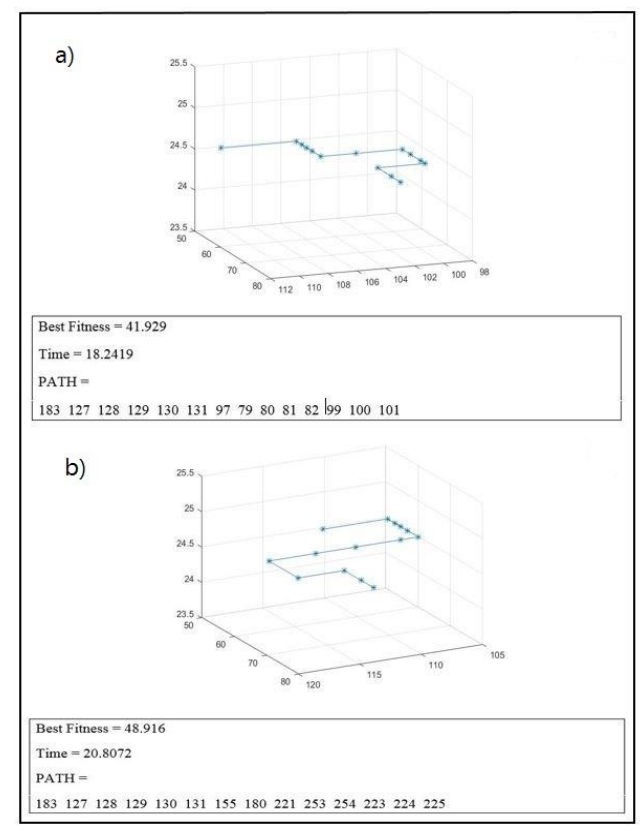

Figure 17. Shortest route (a) Safest route (b)

5.2.5 Scenario 5: In this scenario, it is assumed that the firstfloor fire occurred in a audio-visual commercial unit and the evacuate is take place from nodes 491 and 490 means the exit gates 2 and 3 of the building for the safest and shortest routes, respectively (see Figure 18).

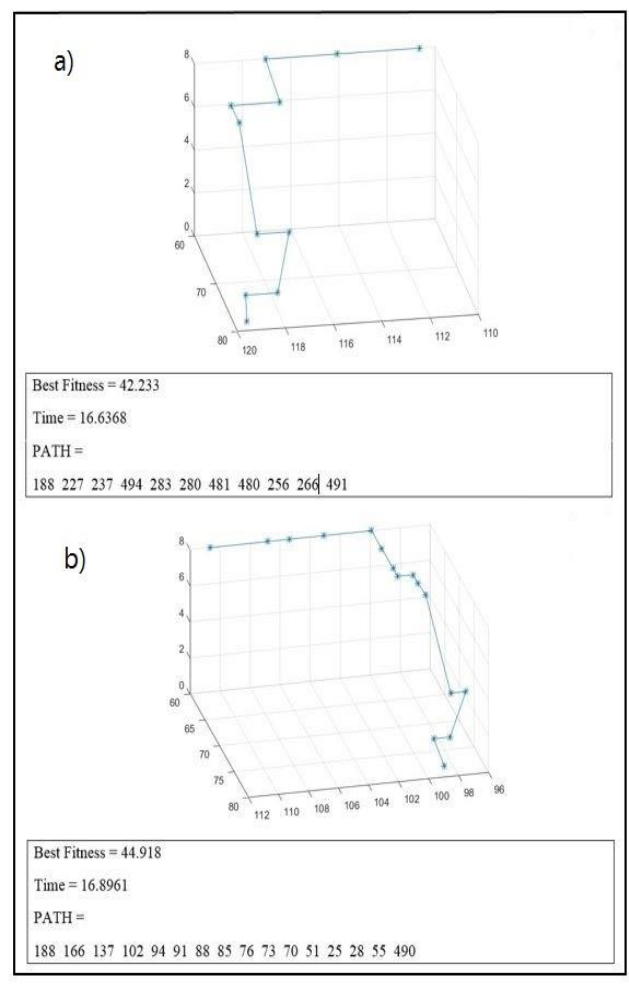

Figure 18. Shortest route (a) Safest route (b) 
5.2.6 Scenario 6: In this scenario, it is assumed that the fire occurred on the ground floor and in the facility room and the evacuate is take place at point 417 means the exit gate 1 (see Figure 19).

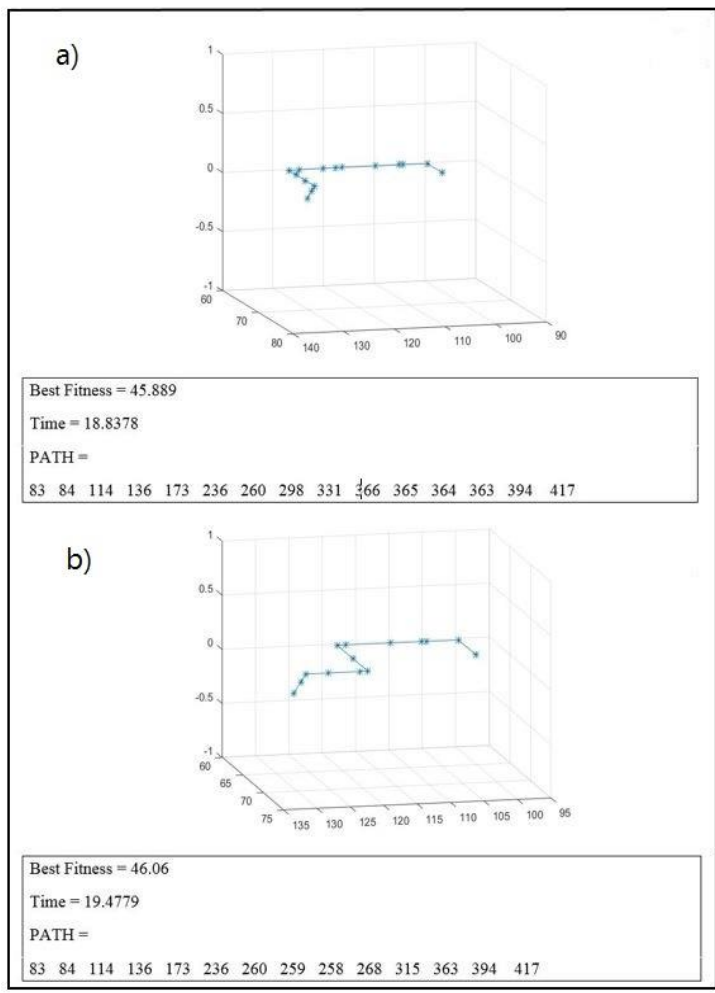

Figure 19. Shortest route (a) Safest route (b)

The following summarize the comparative results of the shortest and safest routes based on processing time, route length and evacuate time in Table 1 . Also the routing results based on the 6 fire building scenario by Network Analysis in ARCGIS environment and Ant Colony algorithm in MATLAB environment were compared in terms of processing time, route length, which are summarized in Table 2.

\begin{tabular}{|c|c|c|c|c|c|c|}
\hline \multirow{2}{*}{ ITEM } & \multicolumn{2}{|c|}{ SHORTEST ROUTE } & \multicolumn{3}{c|}{ SAFEST ROUTE } \\
\cline { 2 - 7 } SCENARIO & $\begin{array}{c}\text { Process } \\
\text { time }(\mathrm{s})\end{array}$ & $\begin{array}{c}\text { Route } \\
\text { length (m) }\end{array}$ & $\begin{array}{c}\text { Evacuate } \\
\text { time (s) }\end{array}$ & $\begin{array}{c}\text { Process } \\
\text { time (s) }\end{array}$ & $\begin{array}{c}\text { Route } \\
\text { length (m) }\end{array}$ & $\begin{array}{c}\text { Evacuate } \\
\text { time (s) }\end{array}$ \\
\hline Scenario 1 & 2.10 & 86.502 & $77.85+125$ & 2.33 & 86.531 & $77.87+125$ \\
\hline Scenario 2 & 1.48 & 41.929 & $34.93+125$ & 1.62 & 48.916 & $40.76+125$ \\
\hline Scenario 3 & 1.88 & 83.354 & $75.21+125$ & 2.01 & 83.476 & $75.31+125$ \\
\hline Scenario 4 & 1.79 & 63.934 & 64.23 & 1.92 & 72.876 & 71.68 \\
\hline Scenario 5 & 1.53 & 42.233 & 40.74 & 1.56 & 44.918 & 42.99 \\
\hline Scenario 6 & 1.42 & 45.889 & 38.24 & 1.59 & 46.06 & 38.38 \\
\hline
\end{tabular}

Table 1. Comparative results of the shortest and safest routes

\begin{tabular}{|c|c|c|c|c|c|c|c|c|}
\hline \multirow{3}{*}{$\sum_{\text {SCENARIO }}^{\text {ITEM }}$} & \multicolumn{4}{|c|}{ NETWORK ANALYSIS } & \multicolumn{4}{|c|}{ ANT COLONY ALGORITHM } \\
\hline & \multicolumn{2}{|c|}{ Shortest Route } & \multicolumn{2}{|c|}{ Safest Route } & \multicolumn{2}{|c|}{ Shortest Route } & \multicolumn{2}{|c|}{ Safest Route } \\
\hline & $\begin{array}{l}\text { Process } \\
\text { Time (S) }\end{array}$ & $\begin{array}{l}\text { length } \\
\text { (m) }\end{array}$ & $\begin{array}{l}\text { Process } \\
\text { Time }(\mathrm{S})\end{array}$ & $\begin{array}{l}\text { length } \\
(\mathrm{m})\end{array}$ & $\begin{array}{l}\text { Process } \\
\text { Time (S) }\end{array}$ & $\begin{array}{l}\text { length } \\
\text { (m) }\end{array}$ & $\begin{array}{l}\text { Process } \\
\text { Time (S) }\end{array}$ & $\begin{array}{c}\text { length } \\
(\mathrm{m})\end{array}$ \\
\hline SCENARIO 1 & 2.10 & 86.502 & 2.33 & 86.531 & 26.3615 & 86.502 & 26.6053 & 86.531 \\
\hline SCENARIO 2 & 1.48 & 41.929 & 1.62 & 48.916 & 18.2419 & 41.929 & 20.8072 & 48.916 \\
\hline SCENARIO 3 & 1.88 & 83.354 & 2.01 & 83.476 & 25.1098 & 83.354 & 25.6565 & 83.476 \\
\hline SCENARIO 4 & 1.79 & 63.934 & 1.92 & 72.876 & 23.7079 & 63.934 & 24.7122 & 72.876 \\
\hline SCENARIO 5 & 1.53 & 42.233 & 1.56 & 44.918 & 16.6368 & 42.233 & 16.8961 & 44.918 \\
\hline SCENARIO 6 & 1.42 & 45.889 & 1.59 & 46.06 & 18.8378 & 45.889 & 19.4779 & 46.06 \\
\hline
\end{tabular}

Table 2. Comparative results Network Analysis and Ant Colony algorithm

\section{CONCLUSIONS}

In this study, to determine the shortest and safest routes to a fire building, an ideal internal building information source, the Building Information Model (BIM), was used to provides detailed assessments for emergency management and evacuation, accurate data collection, robust database design and a detailed digital model. Also among the search methods for optimal routes, we consider Network Analysis and Ant Colony algorithm. To that end, we created a 3D network with 494 kodes and 518 edges. The safest routes were generated based on parameters such as load occupancy, flammability, width exit access and distance fire point by Network Analysis and Ant Colony's algorithm. Then the shortest and safest routes were compared in terms of process time, length route and evacuation time.

The resuls of the comparison between short and safe routes in Table 1 shows that in $70 \%$ of the scenarios, scenarios $2,4,5$ and 6 , the length of the safe routes is longer than the short routes, thus processing time as well as the evacuate time associated with considering formula 5 has a direct relationship with the length of the route, it is on the safe routes more than short routes, and in $30 \%$ of the scenarios, scenarios 1 and 3 are approximately equal lengths of short and safe routes, respectively. They also have approximately equal processing time and evacuate time, which is one reason why the short and safe route lengths are identical, that the output point in both scenarios is one point. It is also added to the evacuation time halfway from the fire station to the building, which is 2 minutes and 5 seconds, as it moves from point starting the evacuation route, the fire truck will also move from the station to the building.

Comparison of the results between the Network Analysis and the Ant Colony algorithm in Table 2 shows that the shortest and safest route lengths for the 6 fire building scenarios in the Ant Colony algorithm are equal to the shortest and safest route lengths in the ARCGIS environment. Because of the direct relationship between route length and evacuation time, they also have the same evacuate time, but Network Analysis offer less processing time to find shortest and safest routes related to the Ant Colony algorithm. 


\section{REFERENCES}

Bansal, V.K., Pal, M., 2007. Potential of geographic information systems in building cost estimation and visualization, Autom. Constr. 16 (2007) 311-322.

BuildingSmart, Building Smart, (2008).

http://www.buildingsmart-tech.org/specifications.

Cao, Y., Lu, F., 2012. Three-Dimensional Modeling for Buildings Evacuation Management. University of Gävle.

Cerovsek, T., 2011. A review and outlook for a 'Building Information Model' (BIM): a multi-standpoint framework for technological development, Adv. Eng. Inform. 25 (2011) 224244.

Choi, J., Lee, J., 2009. [1]3D Geo-Network for Agent-based Building Evacuation Simulation, 3D Geo-Information Sciences, ed. J. Lee \& S. Zlatanova, Springer, pp. 283-299, 2009.

Cova, T.J., Johnson, J.P., 2003. A Network Flow Model For Lane-based Evacuation Routing, Transportation Research, Part A, Policy and Practice, Vol. 37, No. 7, PP. 579-604

Duckham, M., Kulik, L., 2003. "Simplest" Paths: Automated Route Selection for Navigation, Spatial Information Theory, Foundations of Geographic Information Science, ed. W. Kuhn, M. Worboys \& S. Timpf, Editors, Springer Berlin Heidelberg, pp. 169-185, 2003.

Gelido, M.C.L., et al., 2018. 3D Indoor Routing For Fire Evacuation Planning Inside Main Library, Up Diliman. 2018. 42(4/W9).

Karas, I., Batuk, F., Akay, A., Baz, I., 2006. Automatically extracting 3D models and network analysis for indoors, ... 3D Geo Inf. Syst.(2006) 1-10.

Kwan, M.P., Lee, J., 2005. Emergency response after 9/11: the potential of realtime 3D GIS for quick emergency response in micro-spatial environments. Computers, Environment and Urban Systems, 29, pp. 93-113, 2005.

Lee, J., 2001. 3D data model for representing topological relations of urban features, Proc. 21st Annu. ESRI Int. .... (2001) 1-14.

Lee, J., 2007. A Three-Dimensional Navigable Data Model to Support Emergency Response in Microspatial BuiltEnvironments. Annals of the Association of American Geographers, 97(3), pp. 512-529, 2007.

Liu, L., Zlatanova, S., 2012. Towards a 3D network model for indoor navigation, Urban and Regional Data Management, ed. Zlatanova, Ledoux, Fendel \& Rumor, CRCpress/Taylor and Francis Group: London, pp. 79-92, 2012.

Musliman, I.A., Rahman, A.A., Coors, V., 2008. Implementing 3D Network Analysis in 3D-GIS. Int. Arch. Photogramm. Remote Sens. Spat. Inf. Sci. 37, 913-918

NFPA, National Fire Protection Association, (2013). http:// www.nfpa.org/.
Rupple, U., Stuebbe, K., 2008. BIM-based indoor-emergencnavigation-system for complex building, Tsinghua Sci. Technol. 13(2008) 367-367.

Rutger Claes, Tom Holvoet. Ant Colony Optimization applied to Route Planning using Link Travel Time predictions. IEEE International Parallel \& Distributed Processing symposium. 2011 May; 358-365.Tang, F., Ren, A., 2011. GIS-based 3D evacuation simulation for indoor fi re. Build. Environ. 49, 193202. https://doi.org/10.1016/j.buildenv.2011.09.021

Vanclooster, A., Maeyer, P., Fack, V., Van de Weghe, N., 2014. Calculating Least Risk Paths in 3D Indoor Space, Innovations in 3D Geo-Information Sciences, ed. U. Isikdag, Springer International Publishing, pp. 13-31, 2014.

Volk, R., Stengel, J., Schultmann, F., 2014. Building Information Modeling (BIM) for existing buildings - literature review and future needs, Autom. Constr. 38(2014) 109-127.

Xiong, Q., Zhu, Q., Du, Z., Zhu, X., Zhang, Y., Niu, L., Li, Y., 2017. A Dynamic Indoor Field Model for Emergency Evacuation Simulation. Int. J. Geo-Information 1-28. https://doi.org/10.3390/ijgi6040104 